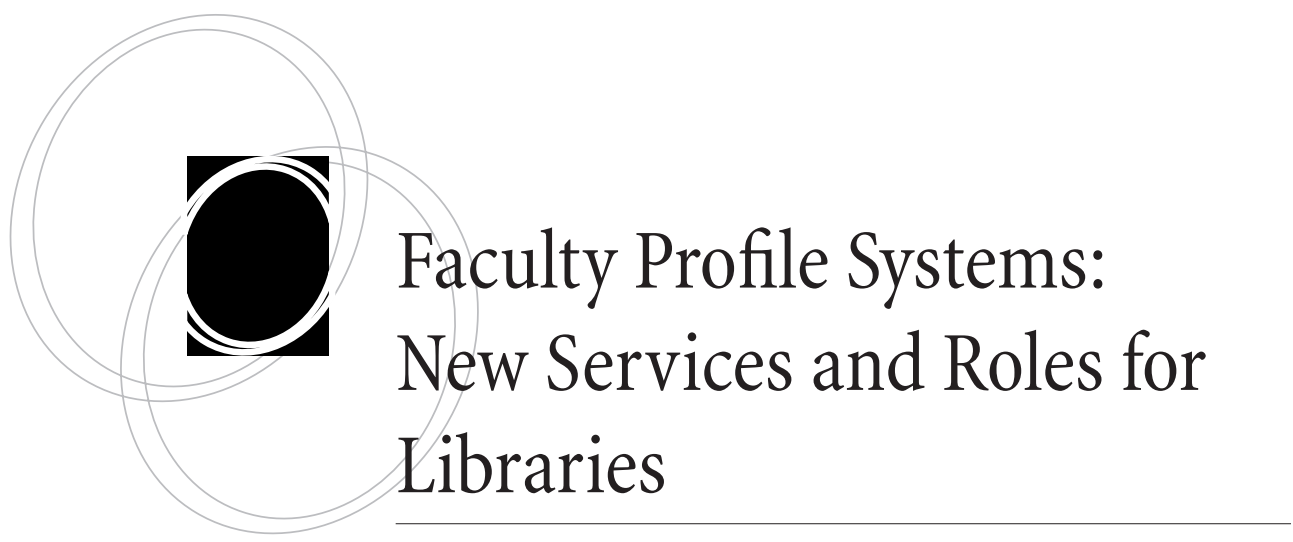

Marlee Givens, Lisa A. Macklin, and Paolo Mangiafico

abstract: Many universities have implemented faculty profile systems that capture faculty and researchers' scholarly outputs and activities. These systems usually include public profiles and tools to help find collaborators or experts. They may be used to create reports for faculty annual reviews or for promotion and tenure, or to assist faculty with complying with open access policies by facilitating deposit in institutional repositories. In many universities, libraries play a central role in the implementation of these systems. This paper explores three case studies showing how and why libraries came into this role and examines some of the consequences of this trend.

\title{
Introduction
}

I n 2010, shortly after a major earthquake in Haiti, Duke University in Durham, North Carolina, began to put together its first humanities lab. Duke aimed to bring together a team of scholars from across the university who had expertise on Haiti and who could "meld a broad array of research questions, methodologies, and social purposes" to create insights, solve specific problems, and engage students in collaborative research and instruction. ${ }^{1}$ The lab began with a core set of scholars who wanted to find colleagues from other disciplines who had relevant expertise on Haiti and with whom they could engage for insights and assistance from diverse perspectives. Several researchers knew about one another's work, but there was no single place that someone could easily find experts on a particular subject, follow links to all of their publications, or see with whom the experts had worked or what courses they had taught.

A natural disaster brings into stark relief the inability to connect colleagues with different expertise to tackle together a common and immediate need. But even in everyday academic life, the difficulty of making connections is a common challenge. Researchers often do not know what the colleague in the next office is working on, and graduate

portal: Libraries and the Academy, Vol. 17, No. 2 (2017), pp. 235-255.

Copyright (C) 2017 by Johns Hopkins University Press, Baltimore, MD 21218.

While the issue of the Portal journal that this article appears in is copyrighted by Johns Hopkins University Press, the article itself is copyrighted by the authors, and made available under a Creative Commons Attribution 4.0 International License. $C C-B Y$ 
students are frequently challenged to identify faculty members with whom they want to do research. With joint programs-such as the combination $\mathrm{MD} / \mathrm{PhD}$ degree in biomedical engineering offered in partnership by the School of Medicine of Emory University and the School of Biomedical Engineering of Georgia Institute of Technology, both in Atlanta-the ability to find experts and collaborators becomes even more challenging.

Universities implement faculty profile systems to fill these and other needs. Profile systems make it easier for faculty to highlight and make accessible their work to a global audience, for students to learn more about their professors and advisers, for university administrators to track and understand the impact of scholarly outputs from programs and grants, and for the media, industry, and the general public to find university experts, among other things.

Central to the implementation and management of faculty profile systems at many universities are libraries. How did libraries become involved in implementing these systems, and why? What can we learn from this, and what trends does this indicate?

\section{The Landscape}

\section{Institutional Repositories}

For many libraries, at least at North American universities, involvement with faculty profile systems began through their connection to institutional repositories (IRs). In 2002, the Scholarly Publishing and Academic Resources Coalition (SPARC) released

In most cases where institutional repositories were implemented, libraries led the way: libraries hosted the systems, provided services around them, and advocated for their use. IR development was often an offshoot of digital library services and offered libraries new opportunities to engage with their faculty. a position paper advocating for IRs. SPARC suggested that repositories could be a component in transforming scholarly communication by capturing, preserving, and disseminating through open access (OA) a university's collective scholarly works. ${ }^{2}$ In most cases where institutional repositories were implemented, libraries led the way: libraries hosted the systems, provided services around them, and advocated for their use. IR development was often an offshoot of digital library services and offered libraries new opportunities to engage with their faculty. Librarians

became involved at earlier parts of the publishing process, collecting and preserving content such as preprints and other works-in-progress and gray (or grey) literaturetechnical reports, papers, and other material that was not published commercially or not generally accessible-in addition to faculty's final published works.

However, it became clear that simply providing a repository service was not sufficient, and "the 'build it and they will come' proposition has been decisively proven wrong." ${ }^{3}$ Researchers had little motivation to make their work available via an IR, and many repositories got little use by their core constituencies. In an attempt to increase 
researcher engagement with institutional repositories, some libraries conducted studies to understand what would motivate faculty authors to deposit their work in an IR. For example, the University of Rochester in New York "endeavored to explore the apparent misalignment between the benefits and services of an IR with the actual needs and desires of faculty," according to Nancy Fried Foster and Susan Gibbons. ${ }^{4}$ The Rochester study of faculty found that "it is essential that anything in an IR be absolutely safe and secure. Beyond that, the single most important criterion of an IR's value to our faculty members is that other people find, use, and cite the work that they put into it." ${ }^{5}$ One approach Rochester implemented was creating a Researcher Page in their IR which "will serve as the showcase for all of the researcher's work." ${ }^{6}$ While some IRs incorporate these profiles into the repository, in many cases profile systems evolved separately and only later became integrated with IRs.

\section{Faculty Profile Systems}

In a 2014 blog post, Lorcan Dempsey, vice president for membership and research and chief strategist for OCLC (Online Computer Library Center), wrote about research information management systems as a potential new service category for libraries. ${ }^{7}$ These systems, which collect and store structured data about faculty publications, research, and scholarly activities, are closely related to, even synonymous with, faculty profile systems. In the United States, these systems appeared in the late 2000s and early 2010s, including commercial systems such as Activity Insight by Digital Measures (http: / / www.digitalmeasures.com/), Elsevier's Pure (https:/ / www.elsevier.com/solutions / pure), Converis by Thomson Reuters (http:// converis.thomsonreuters.com/), and Symplectic Elements (http:/ / symplectic.co.uk/products / elements/); and open-source platforms such as BibApp (http:/ / bibapp.org/), Profiles (http:/ / profiles.catalyst.harvard.edu/), VIVO (http://www.vivoweb.org/), and Opus (https://www.apo.ucla. edu/initiatives/opus/).

For libraries, being involved in the implementation of a profile system can provide opportunities to advocate for positive changes in scholarly communication, such as open access or alternative measures of research impact. The library can also take a more administrative role, such as training users, managing data entry, or curating publications. The library's role often depends on the organizational culture of the institution and may

For libraries, being involved in the implementation of a profile system can provide opportunities to advocate for positive changes in scholarly communication, such as open access or alternative measures of research impact.

be an opportunity for the library to

leverage its involvement in profile system implementation to expand engagement with faculty and administrators on campus.

The following three case studies, as well as other recent scholarship, such as presentations at the spring 2016 Coalition for Networked Information (CNI) meeting in San Antonio, Texas, provide examples of the implementation of such systems and the 
roles libraries can play. ${ }^{8}$ Duke University, Emory University, and the Georgia Institute of Technology (Georgia Tech) were among the first North American institutions to implement Symplectic Elements. Elements integrates with internal (campus) and external data sources and provides tools to curate information about faculty publications, grants, teaching, and professional activities. It can also import citations from Google Scholar and other bibliographic sources, and interface with the VIVO discovery tool and with institutional repository systems. Its capabilities enable researchers to more easily manage their information in one place, a place that they control, and to share the information in as many other places as they wish. As library professionals involved in these implementations, we offer lessons learned and recommendations for our library colleagues who may embark on a similar project.

\section{Scholars@Duke}

\section{Background and Organizational Context}

In the spring of 2010, Duke University's Academic Council (https:/ / academiccouncil. duke.edu/) adopted an open access policy, through which faculty expressed support for an OA model of scholarly communication and granted the university the rights to make scholarly articles they authored freely available to anyone via a digital repository. ${ }^{9}$ The policy called upon Duke Libraries "to develop and monitor a plan for a service or mechanism that would render compliance with the policy as convenient for the faculty as possible." ${ }^{10}$ The libraries had been one of the key proponents of the policy and already had planning underway for a service model that would integrate open access deposit with other processes that were desirable or necessary for faculty to perform.

A DSpace-based institutional repository called DukeSpace (http:/ / dukespace.lib. duke.edu / dspace / ) had been in place since 2006, mostly used as a platform for providing access to theses and dissertations. Although DukeSpace would serve as the core of the program to support the university's new open access initiatives, we knew it alone would not fully meet the needs.

\section{Goals of the Project}

Throughout the process of working with the Academic Council and other university governance committees to develop and adopt an OA policy for faculty research, we thought carefully about how to present a more compelling value proposition for our faculty that would meet their expressed needs, that would motivate them to provide open access on their own, and that would make them want to use repository services. Part of this value proposition was the idea of "negative click repositories" - that is, using the repository service should save you time (represented by mouse clicks) and would provide clear benefits that would be difficult to achieve otherwise. ${ }^{11}$

The library analyzed the issue, reviewing studies such as that by Foster and Gibbons, cited earlier, and holding focus group discussions to identify functions that our researchers or their home departments wanted but currently found cumbersome to accomplish. Among these functions were: 
- the ability to easily showcase one's scholarly work on a personalized profile on the Web and to collect relevant information only once but make it visible in a number of places, such as the university's website, department or lab website, personal websites, printed curricula vitae (CVs), a biographical sketch for a grant proposal, or academic profiles elsewhere

- the ability to populate such profiles largely from existing bibliographic sources, so that researchers need not reenter all of their publications by hand

- the ability for openly accessible scholarly works to be findable via the library catalog, and more importantly, via Google Scholar and other search engines

- the ability to see how many times a work was accessed or downloaded and to understand how others used it or what they said about it, information which could be used in support of career advancement and reward systems

- information and assistance at point of deposit about copyright and open access policies of the publisher, funding agency, or institution related to the work, to help authors make appropriate decisions about where and how they could make their work more widely available.

At the time, we knew of no repository software that could successfully meet all these desires. We began to look for other ways to meet these needs and to partner with other units in the university who were better placed to provide some of them. We were also keen to make sure that our repository and open access services did not stand alone as something only the libraries were concerned about, but instead were well integrated into other processes and functions that had a broader set of stakeholders, as well as stronger influence over faculty workflows and incentives.

\section{Implementation Plan}

In early 2009, staff from the library began to work with partners from the Provost's Office and from the Trinity College of Arts \& Sciences, the undergraduate liberal arts college at Duke, on a proposal for a joint project to support a single faculty data system and mutually reinforce one another's goals. Each of these units was maintaining or developing systems that collected and provided access to a variety of information about faculty activities, and supported a variety of needs. In most cases, these systems were not integrated and were based on technology that was difficult to maintain. In some cases, faculty needed to enter and curate similar data in different places.

Together these units began to plan for a single university-wide approach to meeting these needs that would aim to eliminate inefficient processes and reduce duplicated effort for faculty, improve support for and sustainability of the system, and make data about Duke research and researchers as widely available as possible. As planning progressed, other groups around the university joined the process. A group on the medical side of campus that had supported a home-grown faculty profile system was eager to replace it with a university-supported system when they learned about it. The Office of News and Communications sought better ways to showcase Duke researchers and their work and to track media attention, and so that office was also interested in the new project.

The core project team began to investigate potential tool kits to meet the goals of the various stakeholders, with the assumption that no single system would perform all of 
the functions, and that the outcome would likely depend on an integrated set of tools. There was also a preference for open systems-open source, or more importantly, community source: systems that were built by stakeholders, whose growth was based on community needs, and whose direction would continue to be shaped by that community.

With guidance from a steering committee composed of key faculty and members of university leadership, and with input from focus group discussions with other stakeholders, an implementation team evaluated many options. The team eventually settled on VIVO, partly because of its strengths as a hub that could draw in data from many sources and expose those data in a standardized semantic Web model, providing common formats to facilitate the exchange of data in addition an attractive Web interface. VIVO also already had a large and growing community of institutional users and contributing developers around it. Despite the system not being fully mature in early 2010, the trends for its growth looked good.

However, the team found the editing interfaces and workflows for VIVO lacking, and members of the planning team from the library, in particular, sought a system that would connect to bibliographic databases, to SHERPA / RoMEO (http: / / www.sherpa. ac.uk/romeo/index.php), our DSpace repository, and to other functions that would make maintenance of publication lists and repository deposit easier for authors. While looking for options to better support these functions, we began to evaluate Symplectic Elements. It was capable of many of the functions we had imagined, but some within the team resisted adopting it, partly because of the cost, and partly from the desire to not mix commercial (and Windows-based) vendor software such as Elements with open source systems such as VIVO. After more testing and analysis of other options, the team agreed to move forward with a pilot of Elements, using it only for the publications aspects of the broader VIVO-based project. At that time, Symplectic, a British firm, had no United States customers, and it took time to work out arrangements and contracts for Duke's implementation. A pilot began in late 2011.

The library took primary responsibility for Elements and for assisting faculty with maintenance and deposit of publications. The team in the Provost's Office and Office of Information Technology would be responsible for the implementation of the VIVO hub, feeds and inputs of other kinds of profile information, the interface, APIs (application program interfaces) that would allow software programs to communicate with one another, and widgets that made the data available for a wide variety of uses. The library Elements implementation team worked with staff from Symplectic to set up a test server and make a connection to a test instance of our DSpace repository. During a pilot phase, subject liaison librarians tested how well Elements' bibliographic harvesters worked for different disciplines and used the results to plan for how to improve searching for publications in diverse use cases. This pilot also provided insights into how best to engage with faculty to help develop their publication lists and encourage deposit of their publications to the open access repository via Elements. During this period, we also worked intensively to clean up and import publications metadata from legacy systems to reduce the amount of effort required for faculty profiles to be kept up to date in the new system.

The plan was to introduce the system by school, with some who were eager to move forward quickly (such as the School of Medicine) going first, and others who were less 
eager (such as Trinity College of Arts \& Sciences and the School of Law) later in the process. Some on the steering committee discussed ambitious goals of seeking full faculty participation within a year, and others suggested a more measured approach: aim to please the estimated 20 percent of faculty who were eager "early adopters" initially, making sure they had a good experience and that the system was both useful and easy for them to use. Engagement of a second group of approximately 60 percent of faculty could presumably then be made easier by positive word of mouth from colleagues who preceded them and already had complete profiles. An estimated 20 percent might then remain who would not participate unless required-we decided that it was best not to pressure people in this category early on because it would create a negative impression of the system and process. Instead, we decided to circle back and provide them with more support and incentives to participate after a majority of other faculty were successfully using the new system.

\section{Actual Implementation}

In January 2013, the implementation team made a final automated load of publications from the legacy systems and disabled the ability to continue to update in those systemsgoing forward, all changes would happen in the new system. Both Elements and VIVO (locally named Scholars@Duke, http:/ / scholars.duke.edu) launched in spring 2013 to faculty in the School of Medicine, which, with over 2,000 faculty, is Duke's largest school. Other schools followed in summer and fall of 2013 and early 2014.

In each case, the Scholars@Duke team worked closely with dean's offices and school communications staff to inform faculty about the new program and to encourage engagement with it. Members of both the VIVO and Elements support teams attended many faculty department meetings (often accompanied by liaison librarians); met individually with chairs, deans, and other academic leadership; and offered scheduled and ad hoc training sessions as well as regular office hours when faculty could drop in for an introduction or assistance. Perhaps more importantly, a network of "power users" (http: / / about.scholars.duke.edu/ locate-power-user) was established-individuals in each academic department or division who would act as the first point of contact and support for faculty in that area and as a liaison to the core team to address questions that they could not handle. This group meets monthly to talk about upcoming changes, share information about areas of difficulty, request improvements, and provide mutual support. In communications about their role in supporting curation of faculty publications as part of this project, library staff always included a discussion of open access, both why and how faculty could deposit their own publications to make them more widely available via their profiles, and how to understand Duke's policies as well as funding agency and publisher policies regarding open access.

For the library team, after implementation across all schools stabilized, the focus returned to promoting the aspects of the system that related to open access. In the Scholars@Duke system, publications deposited through Elements to the DukeSpace repository appeared with an "Open Access Copy" button adjacent to the relevant publication citation and alongside a "Full Text" button (if a digital object identifier or DOI was available for the publication), a "Link to Item" button (where any other kind of link 
was provided), or both. Whenever we talked with faculty about the system, we conveyed that it aimed to help them make their work available to as many readers as possible, rather than discussing institutional repositories or open access per se. The repository

Whenever we talked with faculty about the system, we conveyed that it aimed to help them make their work available to as many readers as possible. and $\mathrm{OA}$ were, and continue to be, a means to an end, and we tried to focus communication on the ends-making sure faculty work was findable and accessible to more readers, and that faculty were therefore more likely to be rewarded for it. We were careful not to describe open access as a "mandate" or to talk about deposit processes or building an academic profile as having anything to do with "compliance." The goals were always to serve the needs of the researcher, to serve the needs of the institution, and to serve the needs of scholars and scholarship more generally. If we could successfully meet the needs and goals of individual researchers at our institution, the ability to meet the larger goals would naturally follow.

Three years into the implementation, approximately 35 percent of faculty have logged in to Elements from their own accounts, and close to 80 percent have had their publications and profiles updated with the assistance of delegates or research managers. As the program continues to evolve, new approaches (such as personalized e-mail notifications) invite greater engagement, as do new incentives, such as personalized uniform resource locators (URLs), which help find the resources by giving their network location (in the form of scholars.duke.edu/person/firstname.lastname); better search engine optimization (which will make the Duke profile pages more visible in search engine results); and ease of including profile information in annual reports.

TheScholars@Duke program continues as a hub-and-spoke model: the VIVO system is the hub, where data are collected from a number of different systems of record and where profiles can be edited and supplemented, and from which data can be displayed and used in a variety of ways. The Elements system is an input spoke, and the institutional repository is an output spoke, focused on scholarly publications by members of the Duke community. VIVO handles all of the other profile information, such as biographical statements, directory information, courses, grants, professional activities, artistic works, geographic focus, and office hours. While library staff are not central to the implementation of all of these functions, their expertise and contributions have helped the systems and processes in all these areas become better integrated into the scholarly communication ecosystem and into the culture, goals, and workflows of researchers.

\section{Emory FIRST}

\section{Background and Organizational Context}

In March 2011, Emory's Faculty Council passed an open access policy that called "upon Emory University, through its Libraries, to create an Open Access repository of faculty authored scholarly articles." 12 The adoption of the OA policy was the culmination of a year of open access conversations facilitated by the director of the Center for Faculty 
Development and Excellence, the chair of the Library Policy Committee, and the director of the Scholarly Communications Office in the library. During the 2010-2011 academic year, we met with the faculty, or a representative body, of each college and graduate school. The purpose of the OA conversations was for us and for the faculty to listen and learn, and to find the best way for Emory to move forward with an OA policy.

After the OA policy was passed, work began to build an institutional repository for faculty articles. The IR was named OpenEmory and launched in September of 2012. OpenEmory (https: / / open.library.emory.edu /) is a Fedora repository built with a Django application. Several themes emerged as part of the OA conversations with faculty, including that deposit should be as easy as possible and preferably should form a regular part of faculty workflow. By collecting input from faculty, doing usability testing of the software at key points in development, and providing services such as $\mathrm{CV}$ review and mediated, library-assisted deposit, the library streamlined the submission process as much as possible. However, the IR was separate from any other faculty processes or systems at the university.

In January 2013, the university information technology (IT) division began implementing Symplectic Elements. The first step was evaluating the modules of Elements and the data structure. Various tests were conducted on data loads of faculty information from Emory systems, such as profile information from human resources files, grants, and course information, and publications data from external sources such as Web of Science. The Elements software was internally renamed Emory FIRST (Faculty Information on Research, Service, and Teaching).

Also in 2013, the libraries and IT merged to form LITS: Libraries and Information Technology Services. The goal of this merger was to better align various service functions across the Emory enterprise, including IT functions. Merging a service unit with an academic unit also provided the opportunity to leverage the strengths of each to enable strategic change.

\section{Goals of the Project}

The Emory FIRST project provided several important opportunities for individual faculty and for the institution. Emory FIRST captures faculty information within a central system, provides a path for faculty to deposit their scholarly works into the institutional repository OpenEmory, and facilitates making selected faculty information and their scholarly works publicly available in OpenEmory to promote the faculty and their work. The overall strategic goals of the project include:

- establish an authoritative source of faculty profiles and activities data

- promote faculty through information-rich profiles and Web pages

- enhance discovery by creating links between profiles and content

- create mechanisms to measure impact of research and scholarship.

The project also provides opportunities for the various stakeholder groups. For IT, the project gives a chance to expand the services supporting the research enterprise. For the libraries, using Emory FIRST as the pathway for faculty to deposit their scholarly works into OpenEmory provides the opportunity to meet the desire expressed by faculty 
to have deposit in the IR be a part of their regular work. Implementing Emory FIRST also creates the opportunity to streamline the time-consuming work of scholarly assessment, which was being supported by librarians. For the schools, it provides a single source of information on faculty publications that could feed into other evaluative systems, such as promotion and tenure processes, and produce public profiles that are automatically updated from a single data source.

\section{Implementation Plan}

The initial project team consisted of members of the university's IT division and focused on the technical implementation. The members of IT brought a critical understanding of data, processes, and systems to the project. The School of Medicine, with over 2,000 faculty members, was an early adopter of Emory FIRST. The CV, tailored to the needs of the school, has served as the standardized format for annual reporting for faculty and promotion and tenure. To successfully transition to a faculty profile system, two of the largest departments in the School of Medicine, the Department of Medicine (about 700 faculty members) and the Department of Pediatrics (about 350 faculty members), were selected as pilot groups. In addition, a faculty advisory group was created, as were groups of faculty for user acceptance testing.

The first task was to populate Emory FIRST with faculty activities. The initial loads of data included personal information from human resources systems. The next step was to configure the professional activities module based on the School of Medicine CV template and to populate the professional activities, publications, and grants modules. To populate the professional activities and grants modules, the IT division hired data entry specialists who entered information into Emory FIRST from the CVs of faculty members.

The faculty of the School of Medicine are prolific authors, often authoring or coauthoring hundreds of articles over the course of their career. Therefore, populating the publications module for the faculty of the School of Medicine was no easy task. First, the citations for the publications of each faculty member had to be harvested from bibliographic sources and loaded into a pending queue. Second, each publication had to be "accepted" or verified by the faculty member or their designated proxy. Two approaches were assessed for verifying publication information, a data entry specialist accepting publications on behalf of a faculty member using the instructor's CV as a reference, and the faculty member accepting his or her own publications. For a faculty member with more than 300 publications on his or her $\mathrm{CV}$, a data entry specialist took approximately two and a half days to complete a review. In contrast, a faculty member took approximately 15 minutes to complete a review of his or her own publications. Based on this information and user acceptance testing sessions, the most efficient approach was to pre-populate the pending queue for each faculty member and have him or her accept the listed publications. The product manager of Emory FIRST approached the Woodruff Health Sciences Center Library about partnering on populating the publications module for the School of Medicine faculty. The librarian responsible for publication reports and scholarly assessment for health sciences faculty was assigned to the Emory FIRST project to advise and assist with the population of the publications module for the School of Medicine because she is proficient in search settings for bibliographic sources and the vagaries of name disambiguation. 
The Scholarly Communications Office also came into the implementation planning because OpenEmory already included over 5,000 faculty-authored articles, and the team hoped these could be leveraged for the Emory FIRST implementation. Symplectic also offered the ability to code and implement a connector from Elements into OpenEmory. Having the ability for faculty members to deposit content into the institutional repository from the same system in which they maintain their publications would finally fulfill the stated desire and expectation of faculty members that depositing in OpenEmory simply be a part of regular faculty workflow. The connector from Emory FIRST into OpenEmory was

While the professional activities, grants, and teaching modules of the profile are certainly useful, the publications module can most easily be populated through external sources, and the immediate benefit for annual reports and publications reports for promotion and tenure reviews justifies the investment in resources. implemented in early 2015. In early 2016, the OpenEmory repository was expanded to accept additional content types from Emory FIRST, including books, book chapters, conference papers, posters, presentations and reports.

\section{Actual Implementation}

The various tests with Emory FIRST during the implementation of the School of Medicine pilot departments have demonstrated that populating the publications module first often has the most immediate benefit. While the professional activities, grants, and teaching modules of the profile are certainly useful, the publications module can most easily be populated through external sources, and the immediate benefit for annual reports and publications reports for promotion and tenure reviews justifies the investment in resources.

In the summer of 2015, the Goizueta Business School chose to use the publications module of Emory FIRST for internal administrative recording and analysis of faculty publications. The librarians in the Business Library, using current CVs of faculty, prepopulated the faculty profiles with publications. Administrative assistants in the Business School manually entered the publications that could not be imported.

In the spring of 2016, the Nell Hodgson Woodruff School of Nursing also chose to implement the publications module of Emory FIRST. The Woodruff Health Sciences Center Library assisted with setting up the searches of external sources to populate the publications and with training the Nursing School faculty on using and maintaining their publications in Emory FIRST.

In the summer of 2016, the population of the publications profiles of all School of Medicine faculty was completed. A contract librarian was hired to assist with this work and has been instrumental in completing the population of publications in a timely manner. The next phase, based on the input of the School of Medicine Faculty Advisory Board, will be to fully implement the publications module by training faculty in how to maintain their profiles and publications. This will rely on administrators setting expec- 
tations and providing sufficient training to faculty and their assistants for a successful transition to the new system. The School of Medicine is interested in using the Emory FIRST publications data, including the $h$-index calculated by the system, a measurement based on a combination of a scholar's most cited papers and the number of citations he or she has received in other publications, in promotion and tenure decisions.

Also, to provide public profiles on the Web, a feed of faculty profile information and publications is being created from Emory FIRST to Cascade, the content management system used to populate Web pages at Emory. This feed will provide the opportunity to dynamically update existing faculty Web pages, and the link to full text in OpenEmory will be included. With the implementation of the feed from Emory FIRST to the Web pages of School of Medicine faculty, results from this project will be publicly viewable for the first time. Since each school will decide whether or not to implement Emory FIRST, we hope that as the School of Medicine and School of Nursing complete their implementations, the benefits of Emory FIRST will become apparent and will promote interest from other schools at Emory.

\section{GTScholar}

\section{Background and Organizational Context}

In 2010, Georgia Tech released a 25-year strategic plan for the institute, outlining a set of values and goals to guide strategic directions and support infrastructure for research,

Project sponsors believed that the library's neutral position on campus would benefit the adoption of the profile system by faculty, and that the library could bring expertise in the area of publication data sources and metadata. teaching, and service. Among the core values are high standards of excellence, a desire for global impact, problem-solving and leadership, and an innovative and entrepreneurial culture. The strategic goals for 2010 and beyond, driven by these values, include the support of "faculty-led initiatives for transformative interdisciplinary research" and a drive to "improve all support functions and processes" in the pursuit of institutional effectiveness. ${ }^{13}$ One outcome of this new strategic plan was the

establishment of a Strategic Technology Investment Committee, charged with evaluating new technology proposals and assessing their alignment with the institute's goals and strategies. Within this environment, a group of faculty and staff from across campus began to discuss the implementation of a faculty profile system.

With the dean of libraries and the executive vice president for research as executive sponsors, the faculty profile system proposal included input from the Georgia Tech Research Institute, the Office of Information Technology, the Office of Sponsored Programs, and the Ivan Allen College of Liberal Arts. A team of faculty and staff from these units examined several existing profile systems and recommended that Georgia Tech implement Symplectic Elements. Upon approval of the project proposal in 2012 by the Strategic Technology Investment Committee, the library joined with the Georgia 
Tech Research Institute and the Office of Information Technology as coleaders for the implementation and promotion of the system on campus. Project sponsors believed that the library's neutral position on campus would benefit the adoption of the profile system by faculty, and that the library could bring expertise in the area of publication data sources and metadata. The library, having started a DSpace institutional repository (SMARTech, https: / / smartech.gatech.edu / ) in 2004, was interested in any profile system functionality that might encourage and enable more faculty to self-deposit open access manuscripts into the repository.

\section{Goals of the Project}

The system — branded as GTScholar—would provide an understanding of Georgia Tech's overall research enterprise; reduce the administrative burden of tracking and reporting information about faculty; promote interdisciplinary research by offering tools for collaboration and finding expertise; and improve support processes by capturing data on research and scholarly activities and repurposing those data in a variety of ways. In addition, such a system would streamline the deposit of open access manuscripts into the institutional repository SMARTech. (Georgia Tech faculty would adopt an open access policy in 2012, making this functionality even more desirable.) The ideal faculty profile system would capture researchrelated information, including publica-

The ideal faculty profile system would capture research-related information, including publications and scholarly activities; enable discovery of expertise; promote research networking; repurpose data for other online systems and interact with campus systems; and provide reporting, benchmarking, and measurements of research impacts. tions and scholarly activities; enable discovery of expertise; promote research networking; repurpose data for other online systems and interact with campus systems; and provide reporting, benchmarking, and measurements of research impacts. In this way, the profile system would benefit not just campus administrative units but also faculty who feel burdened with tedious reporting requirements in annual evaluations, proposal preparation, and promotion and tenure package preparation. The team envisioned a central clearinghouse of data from internal campus sources (such as human resources files, grants information, and courses taught), external sources (publications), and manual input from faculty CVs.

\section{Implementation Plan}

In early 2013, the library, the Georgia Tech Research Institute, and the Office of Information Technology formed a steering committee for GTScholar and organized three teams of faculty and staff from across campus to begin planning and implementing the system. The three teams were an implementation planning team and a customer advisory team, both led by the library, and a technical team led by the Georgia Tech Research Institute and the Office of Information Technology. One chief advantage for the library in this effort 
was the ability to leverage existing campus partnerships, including the Library Faculty Advisory Board and relationships with schools and colleges through liaison librarians, to reach faculty across campus who might serve on the profile system advisory groups.

In the first year, the implementation planning team focused on how to set up the Elements system. Georgia Tech opted to use all available system modules to capture the complete picture of faculty scholarship and activities: publications, grants, teaching activities, professional activities, and researcher profiles. In 2013, only the publications module had a well-developed data structure and elements; the implementation planning team would define the data elements for teaching and professional activities. Some data elements were structured according to the incoming campus data feeds (for example, course data from the Banner student information system). Other data elements were defined according to sample CVs and faculty activity reports from across campus. Metadata specialists from the library analyzed these samples and provided input on common data captured in these documents. Faculty members in the implementation planning team also recommended data types and elements they would want the system to capture.

Another focus for the implementation planning team was how best to promote the profile system to faculty, knowing that Georgia Tech's entrepreneurial culture might hinder buy-in, even in conjunction with other strategic goals. Together with the customer advisory team, the planning team developed a list of priorities for outputs, or "products," which might encourage faculty acceptance of the system as a time-saver through the reuse of captured data. Among the highest priority products were a faculty annual activity report, a standard resume for promotion and tenure, and feeds of publications for campus websites, all populated by data from the GTScholar system. These products also influenced the development of data elements, and as the technical team began to work on requirements for products, they also began to define required data types and fields.

The implementation planning team also developed promotional materials and called for beta testers. The beta test would take place after the planning team and technical team finished defining the data elements and testing the feeds, near the end of the first year of implementation. At the same time, the library began to estimate the time required to enter data for a complete faculty profile. By the end of the first year, the steering committee had a list of priorities: to develop an annual activity report; to reach out to school chairs who might use this report in evaluating faculty; to develop configurable Web feeds for college and school websites; and to provide assistance for data entry, because faculty beta testers made it clear that they did not have time to populate the system. The plan for the second year was to find resources for data entry, pilot the system in two schools whose chairs seemed interested in using the annual activity report, and then build on this momentum to introduce the system to other schools. At this point, the library had some experience supervising data entry staff and took the lead with developing a data entry proposal and budget, although funding was still unsure. The other steering committee members (from the Georgia Tech Research Institute and the Office of Information Technology) began working on the annual activity report and reached out to school chairs, and the library's communications staff developed some marketing materials for school chair presentations. Working with school chairs, the steering committee would refine the annual activity report (used as part of a self-assessment in faculty evaluations) and would leverage the chair's relationship with faculty to encourage adoption of the 
system. Upon successful use of GTScholar for annual activity reporting, the school would take ownership of data entry and profile maintenance.

\section{Actual Implementation}

Based on time estimates for data entry and on the collection of faculty CVs from several schools, the library proposed hiring temporary staff to do data entry with the goal of populating up to 1,200 faculty profiles in GTScholar. Georgia Tech happened to be undergoing a reaffirmation of its accreditation by the Southern Association of Colleges and Schools Commission on Colleges (SACSCOC). Because GTScholar could potentially streamline data collection for reaffirmation, the Provost's Office provided a portion of the reaffirmation budget to hire data entry specialists. The reaffirmation deadline added an element of urgency to the implementation of the profile system. The steering committee collected around 600 faculty CVs for data entry. Temporary data entry staff (working in the

The library trained staff in several schools to enter data on behalf of their faculty and offered expertise in customizing search terms for publications searches.

library), student assistants, and regular staff

in two schools together completed nearly 400 profiles in two years. The library trained staff in several schools to enter data on behalf of their faculty and offered expertise in customizing search terms for publications searches. However, the data entry pilot proved that centralized data entry is not efficient, and it did not increase adoption of GTScholar in Georgia Tech's schools and colleges.

The steering committee desired to show certain measures of success, and faculty buy-in continued to be a challenge. Word of mouth from the press release and advisory groups began to spread, and each meeting of the steering committee with potential stakeholders seemed to result in more ideas for using GTScholar data beyond the priority products identified by the implementation planning team. As one member of the team described it, GTScholar became the "killer app" for any unit on campus that needed authoritative data on Georgia Tech faculty. The technical team was eager to develop any product that might be successful enough to sustain institutional support of the profile system, especially through faculty acceptance, because the system relies heavily on faculty to provide and validate data. Unfortunately, the reaction of most faculty who viewed their profiles or tested the system was negative. Unlike campus administrative units that perceived GTScholar as a "killer app," the faculty did not see that it saved their time as promised. GTScholar could find their publications in online sources, but it could not easily report which publications were peer reviewed (as required for annual review, promotion, and tenure), necessitating manual manipulation of publication data. Full use of the GTScholar modules requires a tremendous amount of manual entry and verification. Faculty did not find GTScholar as easy to use for editing their CV data as the word processor Microsoft Word or the document preparation system LaTeX, and they disliked the lack of customization in the exported reports. GTScholar seemed clumsy when compared with other tools the faculty used for collaboration and networking, such as Google Scholar and ResearchGate. In addition, the faculty did not trust GTScholar as 
an accurate record of their performance and remained suspicious of its use for evaluation, promotion, and tenure.

After three years of engaging with schools and colleges to adopt GTScholar as a faculty profile system, only one school (out of 30 at Georgia Tech) successfully used it for annual activity reporting. Three other schools hired temporary staff or redirected support staff to enter faculty data in anticipation of future use, for reporting or feeding publications to websites. The library ended its temporary data entry program (which proved inefficient) and transitioned toward providing training and education to participating schools and individual faculty users who were creating GTScholar profiles. The level of engagement seen in the four participating schools will likely result in greater success for them than for schools that relied on centralized data entry, but the long-term sustainability of GTScholar remains tenuous with such a slow rate of adoption. Relying on small successes with school chairs, without significant support at a higher administrative level, may result in long-term buy-in across more of the institute. However, without a champion at the college dean or provost level, funding the system will be challenging.

\section{Lessons Learned and Recommendations}

As we look back after several years of work on these projects, we can draw some conclusions about the process and make recommendations to others who may be preparing to embark on similar projects.

First, we all found that implementation can take a long time, requiring patience and a pragmatic approach. Duke, Emory, and Georgia Tech's rollouts were incremental, by group, which allowed us to address a variety of expectations, goals, and needs.

Stakeholders need to
understand that the soft-
ware will evolve and that
the system may not meet
every need on day one.

Attempting to roll out a major system all at once will likely result in a lower level of service for any given stakeholder, which can create bad first impressions. While library, IT staff, and administrative leadership may want to wrap up functional requirements and move quickly through implementation, the success of profile systems is almost entirely dependent on the participation of many people, most of whom will be faculty. Setting expectations is important, and we found it was better to set low expectations that we could exceed, rather than aiming for full campus engagement and complete profiles in a short time line. Stakeholders need to understand that the software will evolve and that the system may not meet every need on day one.

Effective communication and publicity are important. Our experience shows that it is difficult to reach faculty through broad communications. We had much better success through targeted efforts: reaching out to individual departments, presenting at standing faculty department meetings, holding office hours in their spaces, working directly with research managers and support staff in distributed areas, and engaging one-on-one with individual faculty and department chairs resulted in much deeper engagement with faculty. Communications targeted to individuals were also effective. For example, the Elements system can send out e-mail messages addressed to individuals, notifying 
them of the specific number of their publications that it has found through bibliographic harvest and inviting them to review and confirm the publications. Duke found a high level of engagement in the hours and days immediately after these messages go out (currently on a monthly schedule). These messages include information about Duke's OA policy, and how and why to deposit publications for open access, and there was a significant increase in deposits after sending these targeted notifications.

We found that the time required for data entry cannot be underestimated. While simply getting the data into the system is a large and complex set of tasks, maintaining the information is perhaps more complex because it relies on faculty trusting how the data will be used and shared. These systems rely heavily on faculty input, which is earned by trust, and it can take time to build rapport with faculty who may see profile systems as reporting and assessment tools used solely by administrators. Faculty are busy, and they do not welcome additional burdens on their time, nor administrative mandates. If you can show value, and give faculty a stake in their profiles and the processes that build them, use will increase over time. However, making the value proposition for a faculty profile system can be challenging. These

While simply getting the data into the system is a large and complex set of tasks, maintaining the information is perhaps more complex because it relies on faculty trusting how the data will be used and shared. systems are competing with similar services such

as Google Scholar, ResearchGate, and Academia.edu, so it is incumbent on the university to show why institutional systems provide better value to researchers. Faculty also do not enjoy being measured and evaluated, so it is important to emphasize the ways the system can have value to individual faculty, rather than only ways it might be used for assessment. It is important to have administrative support for the project as well as for faculty to see that librarians play a critical role in supporting their needs, and do not just enforce compliance of administrative requirements. For public services librarians and liaisons, speaking to faculty about the profile system can serve as an opening for other conversations with faculty around open access; statistical analyses of publications (that is, bibliometrics); networking with fellow researchers; and showcasing their research through online profiles.

There will be variability between campus units and among disciplines in their incentives for using a profile system, in their needs for system functionality, and in their perception of administrative programs. In general, scientists seemed to accept participation in the profile and open access programs without fuss, and where they had questions or concerns, they were very specific. Some humanists, on the other hand, seemed more attuned to potential impacts on university presses and scholarly societies and on assessment, tenure, and promotion. These scholars raised broader and more complex questions about these issues, which needed to be addressed with nuance and sympathy. Faculty may also more readily adopt a system that immediately worked well for them. All of us heard concerns from certain units about the time it would take to maintain their university profiles and their need for more assistance. 
Organizational culture plays a significant role in a successful implementation. Duke, Emory, and Georgia Tech are all large research institutions, each in their own way "multiversities" of diverse units. In each of our implementations, we strove for buy-in from stakeholders in the schools and tried to build visible successes with early adopters, which served as examples when engaging with other areas perhaps less eager for change. Partnerships and collaborations are very important, especially among the library, IT,

Libraries are adept at collaboration, faculty engagement, and nuanced communication around such topics as the open access policy. and campus administration. Administrative units, especially IT units, may have a culture more focused on completing specific tasks and functional requirements, and on compliance with mandates. Libraries are adept at collaboration, faculty engagement, and nuanced communication around such topics as the open access policy. However, if the faculty profile system is perceived as only a library initiative, or only an initiative of IT or central administration,

it will be more difficult to get necessary engagement, and therefore more difficult to implement and sustain.

Finally, it is critical that such programs have strong support from university leadership, from the beginning and throughout implementation. The contributions of many units and individuals will be needed for the program to succeed, and each will likely see the program from a different perspective, have different expectations, and employ different measures of what success means to them. A common vision and shared understanding of the goals and values of such a program among provost, deans, and leaders of units such as the library and IT is essential to ensure that the program stays on track and keeps the end goals in mind while the details of implementation are worked out.

\section{Conclusions}

While the implementation of faculty profile systems at Duke, Emory, and Georgia Tech followed paths that were unique to each institution, there are common lessons learned. At its heart, a faculty profile system is a central database of faculty activities that can be used to showcase the work of the university, produce reports, compare faculty productivity, and assess success, but it must also meet the needs and incentives of the individual faculty members who will use it.

For an implementation to be successful, there must be trust. In working toward implementation, it is important for libraries to keep their focus on their enduring mission and key strengths. The libraries risk being perceived as simply an arm of the administrative (some might say bureaucratic) functions of university leadership, but the libraries also have an opportunity to help the university's researchers take greater control of their scholarly outputs and increase the reach and impact of their work, for their own benefit and for the good of society more generally. Libraries and librarians are usually seen as trusted partners for faculty and students, and we can use these strengths to advocate for and support their needs and goals as faculty profile systems evolve and become an essential part of the scholarly ecosystem. 
However, implementing a faculty profile system is a complex set of tasks that also requires technical expertise and knowledge of internal university systems, which are often unfamiliar to librarians. These projects highlight the potential benefits of collaboration between librarians, information technologists, and faculty to facilitate a successful implementation. Each brings an understanding of a piece of the greater whole. For example, the use of a faculty profile system to support open access policies by facilitating deposit to an Libraries also have an opportunity to help the university's researchers take greater control of their scholarly outputs and increase the reach and impact of their work, for their own benefit and for the good of society more generally. institutional repository may not be high on the list for IT, but librarians understand that faculty often want to share and promote their work, and that integrating this with other necessary workflows can provide benefits to both the individual and the institution.

The growth in the number of software solutions for faculty profile systems indicates that this new set of tools is growing in importance. These new programs provide an opportunity for librarians to play a part in the transformation of the scholarly communication ecosystem and to help faculty promote their work via profiles that they can curate. Profile systems sit alongside new tools such as altmetrics (http:/ / altmetrics.org/), which proposes alternatives to impact factors, $h$-indexes, and other more traditional citation impact metrics; and ORCID (Open Researcher and Contributor ID, http:/ / orcid.org/), which is a persistent digital identifier that distinguishes each researcher from every other researcher, incorporating these as well as traditional bibliographic tools that capture the record of faculty scholarship. In the end, the tools themselves matter less than the opportunities they provide for librarians to serve as guides through the ever-changing scholarly communication landscape.

As universities increasingly become more interdisciplinary and international, and develop joint programs between institutions, data in profile systems that are well integrated into the scholarly process and are seen as providing useful functions to individual researchers can also successfully support much broader goals. Returning to the example we opened with, collaborations formed at the Haiti Lab at Duke launched a number of interdisciplinary projects. ${ }^{14}$ One of them involved historians, information scientists, and an undergraduate research team who put the 2010 Haiti cholera outbreak into historical context. The group published an article in the Centers for Disease Control and Prevention journal Emerging Infectious Diseases ${ }^{15}$ and developed an interactive visual time line (http: / / caribbeancholera.org/) that provided important context for epidemiologists and public health officials to develop appropriate policies and practices to prevent further spread of the disease.

Faculty profile systems, and the libraries and librarians that help make them successful, can enable scholars from diverse backgrounds to find one another, learn from one another's work, form new collaborations, and highlight and share their research in ways that lead to real-world benefits. As information sources and research methods continue to evolve, the public service role of libraries can and should develop with them. Librar- 
ians' knowledge of bibliographic databases, search settings, and name disambiguation are unique and essential skills for populating the publications section of a faculty pro-

Faculty profile systems, and the libraries and librarians that help make them successful, can enable scholars from diverse backgrounds to find one another, learn from one another's work, form new collaborations, and highlight and share their research in ways that lead to real-world benefits. file system. However, it is librarians' knowledge and understanding of the larger evolving scholarly ecosystem that enables them to guide researchers through the use of new tools and approaches, and to provide context for researchers on how and why these tools and approaches can benefit both them as individuals and the larger community. In addition to continuing to help connect local researchers with relevant information from elsewhere, programs such as those described

here provide examples of how libraries can also assist researchers in connecting with one another and with a broader public. In so doing, libraries can help the knowledge produced by their institution find appropriate audiences that can use and expand on it, continuing the scholarly tradition of building on previous discoveries and so "standing on the shoulders of giants."

Marlee Givens is strategic initiatives manager and subject librarian for modern languages at the Georgia Tech Library in Atlanta; she may be reached by e-mail at: marlee.givens@library. gatech.edu.

Lisa A. Macklin is director of the Scholarly Communications Office at Emory University in Atlanta, Georgia; she may be reached by e-mail at: lisa.macklin@emory.edu.

Paolo Mangiafico is the coordinator of scholarly communications technology at Duke University in Durham, North Carolina; he may be reached by e-mail at: paolo.mangiafico@duke.edu.

\section{Notes}

1. Franklin Humanities Institute, Duke University, “About the Haiti Lab,” http:/ / sites.fhi. duke.edu/haitilab/about/.

2. Raym Crow, "The Case for Institutional Repositories: A SPARC [Scholarly Publishing and Academic Resources Coalition] Position Paper," ARL [Association of Research Libraries] 223 (2002): 1-4, http:/ / sparcopen.org/wp-content/ uploads / 2016/01/instrepo.pdf.

3 Dorothea Salo, "Innkeeper at the Roach Motel," Library Trends 57, 2 (2008): 98-123, https: / / muse.jhu.edu / article/ 262026.

4. Nancy Fried Foster and Susan Gibbons, "Understanding Faculty to Improve Content Recruitment for Institutional Repositories," Online Submission 11, 1 (2005), http:/ / www. dlib.org/dlib/january05/foster/01foster.html.

5. Ibid.

6. Ibid.

7. Lorcan Dempsey, Lorcan Dempsey's Weblog, http:/ / orweblog.oclc.org/Researchinformation-management-systems-a-new-service-category/. 
8. Michelle Armstrong, Eli Windchy, and Maliaca Oxnam, "It Takes a Village: From Colleagues to Community with New Library-Stewarded Faculty Profiles," https: / / www. cni.org/topics/assessment/ exploring-the-potential-of-new-faculty-profile-systems.

9. Geoffrey Mock, "Faculty Move Forward on Open Access Policy," Duke Today, March 21, 2010, https: / / today.duke.edu/2010/03/ accessvote.html

10 Duke University, "Policy on Open Access to Research," http: / / provost.duke.edu/wpcontent/uploads/FHB_App_P.pdf.

11. Digital Curation Blog, http: / / digitalcuration.blogspot.com/2008/06/negative-clickrepositories.html.

12. Emory Libraries \& Information Technology, Robert W. Woodruff Library, Emory University, “Emory Open Access Policy," March 15, 2011, http:/ / guides.main.library.emory.edu/c. php?g=50081\&p=324331.

13. Georgia Institute of Technology, "Designing the Future: A Strategic Vision and Plan," 2010, http: / / www.gatech.edu/ sites / default / files / documents / georgia-tech-strategic-plan.pdf.

14. Franklin Humanities Institute, Duke University, "Haiti Lab: Research Projects \& Working Groups," http: / / fhi.duke.edu/labs / haiti-lab/ research-projects-working-groups.html.

15. Deborah Jenson, Victoria Szabo, and the Duke FHI [Franklin Humanities Institute] Haiti Humanities Laboratory Student Research Team, "Cholera in Haiti and Other Caribbean Regions, 19th Century," Emerging Infectious Diseases 17, 11 (2011), http: / d dx.doi. org / 10.3201/ eid1711.110958. 
This mss. is peer reviewed, copy edited, and accepted for publication, portal 17.2 